Erratum

\title{
Factors affecting the resistance of cementitious materials at high temperatures and medium[0] heating rates
}

\author{
Dita Matesová · David Bonen · Surendra P. Shah
}

Published online: 18 October 2006

(C) RILEM 2006

Published in Materials and Structures issue 39:4 (RILEM 288), May 2006, pp. 455-469.

Due to an unfortunate turn of events this article was published with erroneous pages 455-462 therefore the correct version of this article is published in its entirety on the following pages and should be regarded by the reader as the final version. 



\title{
Factors affecting the resistance of cementitious materials at high temperatures and medium heating rates
}

\author{
Dita Matesová · David Bonen · Surendra P. Shah
}

Received: 8 December 2004 / Accepted: 13 April 2005

(C) RILEM

\begin{abstract}
The resistance of mortars made of dolomite and quartz aggregate with and without polypropylene fibers has been studied at a nominal heating rate of $30^{\circ} \mathrm{C} / \mathrm{min}$ from room temperature up to $1000^{\circ} \mathrm{C}$. It is demonstrated that the key parameters that affect the performance of plain mortars are volume instability, phase transformation, aggregate dissociation, and permeability. Experimental results point at the major role of aggregate type on mass loss, porosity, volume instability, microstructure, cracking pattern, and mechanical properties. Three thermal zones are identified; low (up to about $300^{\circ} \mathrm{C}$ ), intermediate (about 300 to $600^{\circ} \mathrm{C}$ ), and high $\left(>600^{\circ} \mathrm{C}\right)$. It is shown that in the low thermal zone, the mechanical properties are about the same or better than those at room temperature. The intermediate thermal zone is characterized by a moderate decline of mechanical properties, whereas a rapid decline is registered in the high thermal zone.

Explosive spalling due to pressure built-up of volatiles took place at temperatures over $200^{\circ} \mathrm{C}$. Addi-
\end{abstract}

\section{Dita Matesová}

Institute of Structural Mechanics, Faculty of Civil

Engineering, Brno University of Technology, Czech

Republic

David Bonen

ACBM Centre, Northwestern University, USA; presently:

School of Civil Engineering, Purdue University, USA

Surendra P. Shah

ACBM Centre, Northwestern University, USA tion of polypropylene fibers prevents spalling due to the occurrence of porous and permeable interface between the fibers and the matrix rather than fiber shrinkage or melting.

Résumé La résistance des mortiers produits par lagrégat de dolomie et quartz avec et sans fibres polypropylènes a été étudiée à la proportion du chauffage $30^{\circ} \mathrm{C} / \mathrm{min}$ jusquáa $1000^{\circ} \mathrm{C}$. Les paramètres essentiels influençant la résistence des mortiers simples sont : instabilité du volume, transformation de la phase, dissociation de lagrégat et perméabilité. Les résultats expérimentaux révèlent linfluence importante du type de lágrégat sur la perte de poids, sur la poreusité, linstabilité du volume, la microstructure, la fissure de la surface et les propriétés mécaniques. Trois zones thermiques ont été identifiées; basse (jusquáa environ $300^{\circ} \mathrm{C}$ ), moyenne (environ $300^{\circ} \mathrm{C}$ jusquáa $\left.600^{\circ} \mathrm{C}\right)$ et haute $\left(>600^{\circ} \mathrm{C}\right)$. Il est évident que les propriétés mécaniques dans la zone thermique basse sont les mêmes sinon meilleures que celles de la température de chambre et la zone thermique moyenne est characterisée par une chute modérée des propriétés mécaniques et la chute rapide est enregistrée dans la zone thermique haute.

La destruction explosive causée par la croissance de la pression des gaz sést effectuée aux températures audessus de $200^{\circ} \mathrm{C}$. Des fibres polypropylènes empêchent la destruction explosive causée plutôt par loccurrence de la jonction poreuse et perméable entre les fibres et la matrice que par la contraction ou la fonte des fibres. 


\section{Introduction}

Cementitious materials that are exposed to high temperatures undergo physical and chemical changes. These changes severely degrade their mechanical properties, and compromise the resistance to heat transfer and resistance to fire penetration [1]. Sullivan [2] used fractional factorial method and showed that the deterioration at elevated temperatures cannot be attributed to a single factor, rather it is affected by several parameters including heating rate, w:c, curing, aggregate type fibers, and load. Similar results were reported by Khoury et al. [3]. Malhotra [4] highlighted the role of agg:c on the performance. It is also worth mentioning that the rate of change in properties are related to the heating rate that in turn is related to the way the heat is applied, test conditions, and the geometry of the concrete element(s).

In addition, as the market share of high-strength high-performance concretes is steadily growing, it has been noted that such concretes are more susceptible to damage than ordinary concretes. Such concretes are likely to experience violent explosion (spalling) caused by fire in the temperature range between 200 to about $450^{\circ} \mathrm{C}$ [5-7]. This is because spalling is attributed to a pore pressure buildup during heating and high-strength or high-performance concretes have a denser and less permeable matrix than ordinary concretes. Therefore, spalling is likely to increase with the decrease of w:c or further densification of the matrix by, for example, addition of silica fume [8]. Pressure buildup and spalling are also inversely related to the heating rate and Bazant and Thonguthai [9] used the term 'moisture clog' for a rapidly heated wall.

It has been found that the fire resistance of concrete with a dense matrix can be improved by incorporation of polypropylene (PP) or fibers alike. Small quantities of the latter have mitigating effects on violent explosion. For example, in order to prevent spalling, Bilodeau et al. [10] suggested addition of $3.5 \mathrm{~kg}$ of $20 \mathrm{~mm}$ PP fibers per cubic meter of concrete, but only $1.5 \mathrm{~kg}$ of the finer $12.5 \mathrm{~mm}$ PP fibers per $\mathrm{m}^{3}$ concrete. Others suggested incorporation of 1 to $4 \mathrm{~kg} / \mathrm{m}^{3}[11,12]$.

Provisions, recommendations, and designing of materials at high temperatures are given elsewhere, e.g. [13-16].

Though there is a bulk of literature on the resistance of concrete to intensive fire, only a few papers deal with the effects of high heating rate from a microscale point of view [17]. The objectives of this paper, therefore, are to report on the main reactions that take place at various temperatures, evaluate the effects of siliceous (quartz) and calcareous (dolomite) aggregate on the degradation process, and highlight the role of PP fibers on preventing spalling.

\section{Materials}

Mortars made of Portland cement Type I with either quartz (Ottawa) sand or dolomite sand were prepared at a w:c 0.44 and a nominal agg:c 3.45 by volume. At full hydration, that ratio corresponds to about agg:paste 1.96 by volume. The densities of the quartz and dolomite were 2.65 and $2.76 \mathrm{~g} / \mathrm{cm}^{3}$, respectively. The mix design of the two compositions and the grain size distribution of the sand as calculated from sieve analysis are given in Tables 1 and 2, respectively.

In light of the crucial role of the internal porosity on spalling, an attempt to produce specimens with similar contents of air was made. The air content was determined by comparing the actual densities of the mortar specimens to the nominal one. At the beginning, it was found that the quartz mortar contained about $6.5 \%$ entrapped air. That relatively high value was attributed

Table 1 Mix design of plain quartz and dolomite mortars

\begin{tabular}{lcc}
\hline Constituent & $\begin{array}{l}\text { Quartz mortar } \\
\left(\mathrm{kg} / \mathrm{m}^{3}\right)\end{array}$ & $\begin{array}{l}\text { Dolomite mortar } \\
\left(\mathrm{kg} / \mathrm{m}^{3}\right)\end{array}$ \\
\hline $\begin{array}{l}\text { Portland cement Type I } \\
\text { Superplasticizer }\end{array}$ & 538.2 & 540 \\
$\quad$ polycarboxylate) & 5.92 & 5.94 \\
Tributyl phosphate & 3.2 & - \\
Sand & 1562.1 & 1632.3 \\
Water & 230.9 & 231.7 \\
Total & 2340 & 2410 \\
\hline
\end{tabular}

Table 2 Sieve analysis of sand

\begin{tabular}{rccc}
\hline Sieve no & $\begin{array}{l}\text { Sieve opening } \\
(\mathrm{mm})\end{array}$ & $\begin{array}{l}\text { Quartz } \\
\text { (\% retained })\end{array}$ & $\begin{array}{l}\text { Dolomite } \\
\text { (\% retained })\end{array}$ \\
\hline 6 & 3.35 & & 2.97 \\
8 & 2.36 & & 13.12 \\
16 & 1.18 & & 33.49 \\
30 & 0.6 & 23.11 & 24.76 \\
50 & 0.3 & 76.15 & 16.13 \\
100 & 0.15 & 0.74 & 6.62 \\
200 & 0.075 & & 1.73 \\
$<200$ & $<0.075$ & & 1.08 \\
\hline
\end{tabular}


Table 3 Summary of experiments performed indicating specimens' age, maximum exposure temperatures, and specimens' geometry

\begin{tabular}{|c|c|c|c|c|}
\hline Type of experiment & $\begin{array}{l}\text { Quartz and dolomite } \\
\text { mortars }\end{array}$ & Age (days) & Temperature $\left({ }^{\circ} \mathrm{C}\right)$ & Specimen geometry $(\mathrm{mm})$ \\
\hline Temper. rise in specimens & $\begin{array}{l}\text { No fibers } \\
\text { PP fibers }\end{array}$ & 14 & $\begin{array}{l}1000 \\
-\end{array}$ & Prisms $25 \times 25 \times 180$ \\
\hline Mass loss and strain & $\begin{array}{l}\text { No fibers } \\
\text { PP fibers }\end{array}$ & 14 & $\begin{array}{l}\text { 100-1000 (temp. intervals 100) } \\
-\end{array}$ & Prisms $25 \times 25 \times 180$ \\
\hline Ref. mass loss and shrinkage & $\begin{array}{l}\text { No fibers } \\
\text { PP fibers }\end{array}$ & $14-63$ & Unheated & Prisms $25 \times 25 \times 180$ \\
\hline Accessible porosity & $\begin{array}{l}\text { No fibers } \\
\text { PP fibers }\end{array}$ & 14 & $\begin{array}{l}\text { Unheated, 100-1000 (temp. } \\
\text { intervals 100) } \\
\text { - }\end{array}$ & Prisms $25 \times 25 \times 130$ \\
\hline Permeability & $\begin{array}{l}\text { No fibers } \\
\text { PP fibers }\end{array}$ & 14 & Unheated, 100, 200 & Ctyl. plates $\varnothing 76 \times 25$ \\
\hline $\begin{array}{l}\text { Compressive strength and } \\
\text { modulus of elasticity }\end{array}$ & $\begin{array}{l}\text { No fibers } \\
\text { PP fibers }\end{array}$ & 14 & $\begin{array}{l}\text { Unheated, 200, 300, 500, 600, } \\
\quad 900 \\
-\end{array}$ & Prisms $25 \times 25 \times 130$ \\
\hline SEM & $\begin{array}{l}\text { No fibers } \\
\text { PP fibers }\end{array}$ & $\sim 20$ & $\begin{array}{l}500 \text { and } 600(\mathrm{Q}) \\
\quad \text { unheated and } 200\left(\mathrm{D}_{\mathrm{f}}\right)\end{array}$ & $\sim 15 \times 15 \times 15$ \\
\hline Optical microscope & $\begin{array}{l}\text { No fibers } \\
\text { PP fibers }\end{array}$ & 14 & $\begin{array}{l}400,500,800,1000 \\
-\end{array}$ & Prisms $25 \times 25 \times 180$ \\
\hline
\end{tabular}

to the monosize grain distribution of the quartz grains that did allow for a good packing that was obtained with the dolomite grains. Therefore, tributyl phosphate was added to the mixtures at a dosage of $0.6 \%$ of the cement by weight. This reduced the air content to about $4 \%$; a similar content that was found in the dolomite mortar. The quartz sand was added to the mixtures as received without any conditioning. However, in view of the $4 \%$ moisture found in the dolomite sand; the latter was dried out in the oven at $90^{\circ} \mathrm{C}$ for 24 hours prior to casting.

In some mixtures, PP fibers were added at a constant dosage of $2 \mathrm{~kg} / \mathrm{m}^{3}$. The PP fibers were $13 \mathrm{~mm}$ long, $50 \mu \mathrm{m}$ in diameter, and had a melting point of $152^{\circ} \mathrm{C}$.

Throughout the text, the dolomite and quartz mixtures are designated by the letters D and Q, respectively, and similarly, fiber-bearing mixtures are designated by the symbols $D_{f}$ and $Q_{f}$, respectively.

\section{Experimental procedure}

Mixtures were prepared according to ASTM Test Method 192 [18], cast in molds with various geometries, sealed off in plastic sheets, and cured for the first 24 hours in the molds at a room temperature. At 24 hours, the mixtures were demolded and placed in $\mathrm{Ca}(\mathrm{OH})_{2}$ water-saturated containers at room temperatures for further curing until testing. Table 3 provides a summary of the tests conducted, curing age, exposure temperatures, and the geometry of the specimens.

\subsection{Heating procedure}

The specimens were heated in a programmable muffle furnace at a nominal heating rate of $30^{\circ} \mathrm{C} / \mathrm{min}$ which is in the range of medium heating rates. However, due to temperature losses to the surrounding and insufficient power of the heating elements of the furnace, the heating rate continually decreased to about $10^{\circ} \mathrm{C} / \mathrm{min}$ at $1000^{\circ} \mathrm{C}$. The nominal $30^{\circ} \mathrm{C} / \mathrm{min}$ employed in this research is lower than other time-temperature fire curves developed for various exposures, such as, ISO 834 Standard fire curve, Hydrocarbon or Hydrocarbon modified curve, RWS fire curve, etc. that belong to a group of high heating rate curves in the range of $100-200^{\circ} \mathrm{C} / \mathrm{min}$. 
Once the target temperature was reached, for securing a thermal equilibrium, the specimens were kept at the target temperature for additional $60 \mathrm{~min}$ prior to cooling down to about $150^{\circ} \mathrm{C}$. Then, the specimens were immediately placed in a desiccator. That measure was taken in order to prevent any moisture absorption and further damage to the specimens due to rehydration and conversion of alkali-earth oxides to hydroxides. The latter reaction is especially deleterious in the dolomitic specimens. The results reported for each mixture are the average of three specimens.

The temperature rise was recorded by type $\mathrm{K}$ (alumel-chromel) thermocouple that was embedded at the center of the specimens immediately after the cast. The thermocouple's wires were isolated by a ceramic tube and were connected to a data logger that recorded the temperature at the center of the specimens every 10 seconds.

\subsection{Thermal analysis}

TGA analysis of the dolomite aggregate and cement paste were carried out at a heating rate of $10^{\circ} \mathrm{C} / \mathrm{min}$ in the presence of nitrogen.

\subsection{Mass loss}

Loss of mass due to evaporation of water and $\mathrm{CO}_{2}$ was determined by comparing the mass of the nonheat treated specimen with its final mass after the heating. Other measurements of mass loss were taken in an environmental chamber at a temperature of $22 \pm 1{ }^{\circ} \mathrm{C}$ and $50 \pm 1 \% \mathrm{RH}$ (relative humidity) for indirect determination of the transport properties of unheated specimens.

\subsection{Accessible porosity}

The difference in the porosity of the pre and post heat treated specimens was determined by solvent replacement technique. Because water had to be excluded; otherwise deleterious reactions associated with rehydration of the heated specimens would take place, the accessible porosity was measured by using methanol and isopropyl alcohol.

In order to achieve a water-saturated state, prior to the solvent replacement tests, the specimens were conditioned by immersing them in de-ionized water for 24 hours under vacuum according to ASTM Test
Method C 1202 [19]. The specimens were weighted and the porosity was found by replacing the evaporable water of the water saturated specimens by methanol. For securing a complete replacement of water, the specimens were immersed in methanol for 10 days under vacuum. Because of its good diffusivity and complete immiscibility of water in it, methanol was chosen as a material of choice for specimens that were cured at room temperature and specimens heated up to $100^{\circ} \mathrm{C}$. The porosity was calculated by weight differences pre and post immersion in methanol.

Above $100^{\circ} \mathrm{C}$, isopropyl alcohol substitute for methanol. The former was chosen from a wide spectrum of alcohols because of its relatively high vaporization point in comparison with methanol and other alcohols. Cooled post-heated specimens were placed in a desiccator and evacuated continuously with a vacuum pump for three hours. Consequently, the specimens were immersed in isopropyl alcohol for additional 40 hours, of which vacuum was applied during the first 24 hours.

\subsection{Permeability}

Permeability was measured on unheated specimens and specimens heated to 100 and $200^{\circ} \mathrm{C}$ only. Since neither $\mathrm{Ca}(\mathrm{OH})_{2}$ nor other carbonates decompose at such low temperatures, water was used throughout. Water-saturated state was achieved by immersing the specimens in de-ionized water for 24 hours under vacuum according to ASTM C 1202 [19]. The saturated specimens were placed in the device depicted in Fig. 1 and sealed off with silicone rubber. After the silicone rubber set and hardened, the filling chamber and the

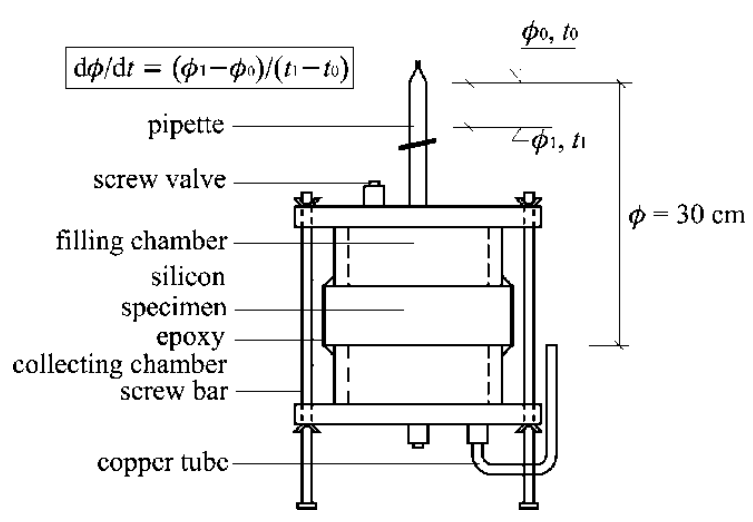

Fig. 1 Device for water permeability test. 
pipette were repeatedly filled with de-ionized water until a steady-state flow was obtained, typically after about 24 hours. The water was drained through the copper tube. After 24 hours, the pipette was refilled so a maximum value of head of about $300 \mathrm{~mm}$ was achieved and the changes in the water level in the pipette were recorded during additional 24 hours. The calculated coefficient of permeability was based on the calculated rate of flow of water between 24 to 48 hours from the beginning of the tests.

According to Darcy (1856) [20], the relationships of permeability and sufficiently slow, steady, and unidirectional flow are:

$q=\frac{-K \phi}{L}$

where $q$ is the flow rate per unit area $(\mathrm{m} / \mathrm{s}), K$ is the permeability constant $(\mathrm{m} / \mathrm{s})$ that is dependant on both the solid and fluid properties of the porous medium, $\phi$ is the energy loss, and $L$ is the length of the sample in the microscopic flow direction. Suppose $Q$ is the flow rate through a unit volume $\left(\mathrm{m}^{3} / \mathrm{s}\right)$ and $A$ is the crosssection area of the specimen perpendicular to the water flow $\left(\mathrm{m}^{2}\right)$, Eq. (1) can be written as:

$q=\frac{Q}{A} ; \quad \mathrm{d} Q=\frac{\mathrm{d} V}{\mathrm{~d} t}=\frac{\mathrm{d} \phi A_{p}}{\mathrm{~d} t}$

where $\mathrm{d} V / \mathrm{d} t$ is the change of the liquid volume in the pipette per time, $\mathrm{d} \phi / \mathrm{d} t$ is the rate of change of the water level in the pipette, and $A_{p}$ is the inner cross-section area of the pipette. By substituting equations (2) for (1) a differential equation with two variables $t$ and $\phi$ is obtained. By integration, and designating $\phi_{0}$ and $\phi_{1}$ as the initial and final level of the water in the pipette, respectively, the permeability coefficient, $K$, is:

$K=\frac{L A_{p}}{A \mathrm{~d} t} \ln \left(\frac{\phi_{0}}{\phi_{1}}\right)$

\subsection{Non-restrained shrinkage}

Steel buttons $152 \mathrm{~mm}$ apart were placed on two opposite sides of each specimen during casting and the irreversible deformation was measured by a portable multiposition strain gauge with accuracy of $0.0025 \mathrm{~mm}$ (0.0001 in). The shrinkage of the unheated reference specimens was measured on 14-day water cured specimens that were placed in an environmental chamber at $22 \pm 1{ }^{\circ} \mathrm{C}$ and $\mathrm{RH} 50 \pm 1 \%$ up to 50 days. The shrinkage/expansion of the post heated specimens was measured after the specimens were cooled down to room temperature in a desiccator.

\subsection{Compressive strength and modulus of elasticity}

Specimens were tested by MTS machine with frame fatigue rating of $500 \mathrm{kN}$ (110 kips) in a deformation controlled mode at a rate of $0.012 \mathrm{~mm} / \mathrm{s}$. Force and deformation were recorded every $0.5 \mathrm{~s}$. The linear part of the ascending branch of the force-displacement diagram was used for calculating the modulus of elasticity in compression.

\subsection{Microstructure - SEM and optical microscope}

Microstructure analysis was carried out by Hitachi S$3500 \mathrm{~N}$ VP scanning electron microscope. Specimens were embedded in low viscosity epoxy, cut with diamond saw in the presence of isopropyl alcohol, polished successively with finer grades of $\mathrm{SiC}$ polishing papers and diamond paste, and coated with $1 \mathrm{~nm}$ thick layer of Au-Pd alloy. The cracking patterns of the surface of the post-heated specimens were viewed by an optical microscope.

\section{Results}

4.1. Resistance of plain mortars to high temperature

\subsubsection{Temperature rise}

Figure 2 shows the rate of the temperature rise $(\mathrm{d} T / \mathrm{d} t)$ vs. the temperature as was recorded at the center of the plain mortars up to $1000^{\circ} \mathrm{C}$. The peaks viewed correspond to the occurrence of endothermic reactions. For convenience, these reactions are grouped into a few thermal zones, according to the nature of the reactions as are provided in Table 4.

Up to about $550^{\circ} \mathrm{C}$, only the cement paste undergoes physical/chemical changes, while most of the common aggregate are barely affected by the rising temperature. 
Table 4 Identification of thermal zones in the dolomite and quartz mortars

\begin{tabular}{|c|c|c|}
\hline Zone & $\begin{array}{l}\text { Temperature } \\
\text { interval }\left({ }^{\circ} \mathrm{C}\right)\end{array}$ & Process \\
\hline A & $<100$ & Release of evaporable water \\
\hline $\mathrm{B}$ & $\sim 100-150$ & $\begin{array}{l}\text { Dehydration of ettringite and } \\
\text { monosulfate }\end{array}$ \\
\hline $\mathrm{C}$ & $\sim 100-300$ & $\begin{array}{l}\text { Release of chemical water from CSH } \\
\text { gel }\end{array}$ \\
\hline $\mathrm{D}$ & $\sim 480-550$ & Dissociation of $\mathrm{Ca}(\mathrm{OH}) 2$ \\
\hline $\mathrm{E}$ & $\sim 573$ & Conversion of $\alpha$ quartz to $\beta$-quartz \\
\hline $\mathrm{F}$ & $\sim 867$ & Conversion of $\beta$-quartz to $\beta$-tridymite \\
\hline $\mathrm{G}$ & $\sim 600-950$ & $\begin{array}{l}\text { Dissociation of dolomite and other } \\
\text { impurities }\end{array}$ \\
\hline
\end{tabular}
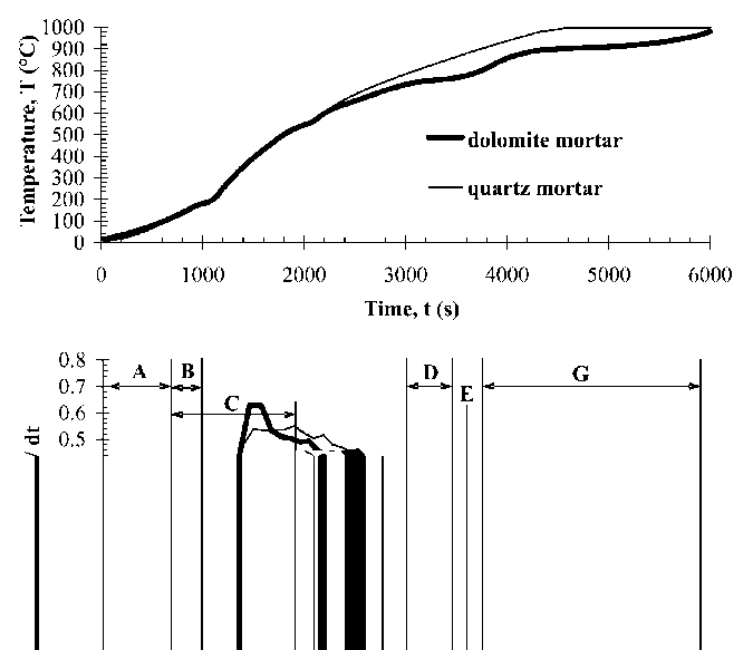

Fig. 2 The effect of composition on the temperature rates of dolomite and quartz mortars at a nominal heating rate of $30^{\circ} \mathrm{C} / \mathrm{min}$. The designated zones and peaks are summarized in Table 4.

In this temperature range, the endothermic reactions in a consecutive order are the release of evaporable water from the cement paste, dehydration of ettringite, monosulfate, and other forms of calciumaluminosulfate that might be present, evaporation of the non evaporable (chemical) water of the C-S-H, and decomposition of calcium hydroxide to calcium oxide.

The effects of high temperature on quartz-bearing aggregate are completely different from the corresponding effects on calcareous aggregate. At room temperature, the stable form of quartz is the $\alpha$ form. At $573^{\circ} \mathrm{C}, \alpha$-quartz is converted to $\beta$-quartz and as temperature increases, $\beta$-quartz is converted to $\beta$ tridymite at $867^{\circ} \mathrm{C}$. At very high temperatures, con- version of $\beta$-tridymite into $\beta$-cristobalite takes place at $1470^{\circ} \mathrm{C}$ [21]. Those inversion temperatures increase as the vapor water pressure increases [22].

In turn, calcareous aggregate dissociates in the range of about $700-970^{\circ} \mathrm{C}$. The nominal dissociation temperatures of pure dolomite and calcite at 1 atmosphere are about $800^{\circ} \mathrm{C}$ and $894^{\circ} \mathrm{C}$, respectively, and these temperatures are increased as the partial pressure of $\mathrm{CO}_{2}$ increases [23]. Dolomite forms incomplete solid solution with calcite and other metal carbonates containing Fe, Mn, etc. Therefore, the dissociation temperature may move up and down according to the exact composition and the contents of other impurities. It is well known, however that the dissociation of ordinary dolomite might start at temperatures as low as about $600^{\circ} \mathrm{C}$.

Since the mortars were prepared at the same agg:paste volume, the differences viewed in Fig. 2 can directly be attributed to the effects of aggregate. Accordingly, the quartz mortar absorbed more heat up to about $150^{\circ} \mathrm{C}$, whereas dolomite mortar absorbed more heat from about 300 to $500^{\circ} \mathrm{C}$ and at temperatures greater than $650^{\circ} \mathrm{C}$. These differences are attributed to the differences in thermal conductivity and dissociation of the dolomite as is discussed below. It also implies that the actual impact of aggregate varies according to the actual agg:c.

Of interest, the endothermic peaks that are associated with the conversion of quartz are hardly detected in Fig. 2. This is probably related to the low heat required. For example, the heat of conversion of $\alpha$ to $\beta$-quartz is $5.9 \mathrm{~kJ} / \mathrm{kg}$ [24], which is fairly low in comparison with the dissociation heat of calcium hydroxide that is $1000 \mathrm{~kJ} / \mathrm{kg}$ [25]. Nonetheless, despite the small heat absorbance associated with the phase transformations of quartz, these reactions are associated with an unavoidable deleterious expansion.

Figure 3 shows the TGA and DTA analyses of the cement paste and dolomite aggregate. The cement paste is characterized by two main dehydration peaks around 120 and $500^{\circ} \mathrm{C}$ that are associated with dissociation of calciumaluminosulfate hydrate and calcium hydroxide, respectively. Also, a continuous weight loss is registered from about 100 to $480^{\circ} \mathrm{C}$. The total weight loss of the cement paste is about $26.5 \%$. In turn, the total dolomite weight loss is about $44 \%$, whereas the theoretical weight loss of pure dolomite is $47.7 \%$. The difference is probably due to the presence of some calcite and clay impurities. Dolomite starts to decompose 
Dolomite aggregate:

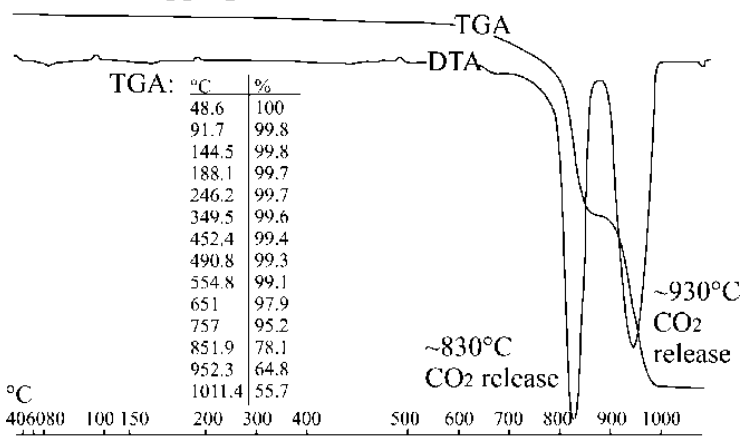

Cement paste:

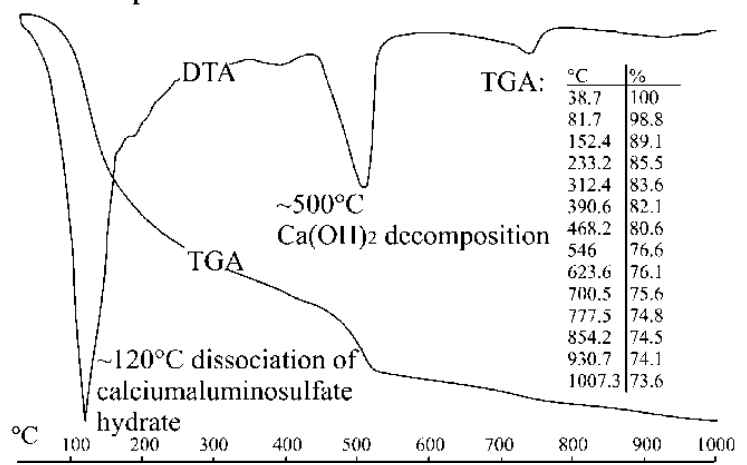

Fig. 3 TGA and DTA analyses of dolomite aggregate and cement paste.

at about $650^{\circ} \mathrm{C}$ and has two prominent peaks at about 830 and $930^{\circ} \mathrm{C}$. Of interest, the latter peaks do not match the counterpart peaks at about 750 and $900^{\circ} \mathrm{C}$ that are viewed in Fig. 2. This mismatch might in part be related to the differences in heating rates and test conditions, and perhaps to other chemical reactions that take place during the heating. In this regard, vari- ations of the dissociation temperature of dolomite are also reported in the literature. Janotka et al. [26] reported on two main peaks at 680 and $750^{\circ} \mathrm{C}$, Engler [27] cited a range of 700 to $785^{\circ} \mathrm{C}$, and Samtami et al. [28] measured two main peaks around 760 and $930^{\circ} \mathrm{C}$. It is worth mentioning that the dissociation temperature is increased as the partial pressure of $\mathrm{CO}_{2}$ is increased. In addition the temperature may move up or down according to the specific composition of the dolomite.

\subsubsection{Mass loss and porosity}

Table 5 provides the values of the mass loss and accessible porosity of the mortars at various temperatures. It was found that these two parameters are well correlated, with correlation coefficients of 1 for the dolomite mortar and 0.91 for the corresponding quartz mortar. Up to $500^{\circ} \mathrm{C}$, the mass loss of both mortars decreases gradually and is slightly higher for quartz mortar. Given that in this temperature range the mass loss is associated with the loss of weight of the cement paste, and because the mortars have the same w:c, the differences between the two sets are related to the differences in densities and rate of release of water. Upon normalizing the densities, the differences become smaller, nonetheless, the mass loss and accessible porosity of the quartz mortar is always greater than that of the dolomite mortar.

As can be expected, the trend of accessible porosity follows that of mass loss with one exception; from room temperature to $100^{\circ} \mathrm{C}$, the porosity decreases in both mortars probably because of further hydration of the cement paste. Up to about $600^{\circ} \mathrm{C}$, the differences in porosity of the mortars are small. However, from
Table 5 Accessible porosity (\% of volume) and mass loss ( $\%$ of weight) of dolomite and quartz mortars after heating

\begin{tabular}{rccccc}
\hline & \multicolumn{2}{l}{ Mass loss $(\%)$} & & \multicolumn{2}{c}{ Accessible porosity $(\%)$} \\
\cline { 2 - 3 } \cline { 5 - 6 } Temperature $\left({ }^{\circ} \mathrm{C}\right)$ & Dolomite mortar & Quartz mortar & & Dolomite mortar & Quartz mortar \\
\hline 20 & 0 & 0 & & 8.0 & 9.8 \\
100 & 1.9 & 2.0 & & 7.0 & 8.7 \\
200 & 6.1 & 6.5 & & 11.5 & 12.5 \\
300 & 7.1 & 7.4 & & 12.9 & 13.7 \\
400 & 7.5 & 8.2 & & 13.9 & 15.5 \\
500 & 8.8 & 9.2 & & 18.8 & 20.4 \\
600 & 11.6 & 10.2 & & 20.8 & 21.1 \\
700 & 15.7 & 10.8 & & 26.3 & 21.4 \\
800 & 29.0 & 10.4 & & 41.2 & 22.1 \\
900 & 40.6 & 10.3 & & 54.4 & 22.3 \\
1000 & 41.2 & 10.0 & & 56.2 & 22.2 \\
\hline
\end{tabular}


$600^{\circ} \mathrm{C}$ and on, the dissociation of the dolomite has a preponderate effect and the dolomite specimens become highly porous. Thus, at $1000^{\circ} \mathrm{C}$ the porosity of the dolomite mortar is 2.5 -fold greater than the porosity of the quartz mortar. The highest rates of mass loss and subsequent increase in porosity of the dolomite mortar take place in the range of 700 and $900^{\circ} \mathrm{C}$ due to the release of $\mathrm{CO}_{2}$.

\subsubsection{Volume instability}

Figure 4 shows the unrestrained linear movement of the specimens at various temperatures. At ordinary temperatures common aggregate does not shrink, rather it is the cement paste that shrinks. Up to a few hundreds degrees Celsius, the thermal expansion of aggregate compensates and may counter the shrinkage of the paste. Therefore, the linear movement and the change from contraction to expansion is affected by both the volume fraction and thermal expansion coefficient of the aggregate. In this study, it is shown that the maximum linear unrestrained shrinkage of the dolomite mortars is $0.045 \%$ at temperatures of about $300-400^{\circ} \mathrm{C}$, and zero expansion is registered at about $450^{\circ} \mathrm{C}$. The corresponding values for the quartz mortars are $0.06 \%$ and about $520^{\circ} \mathrm{C}$, respectively.

At higher temperature, the volume instability patterns of the dolomite mortars are completely different from the companion quartz mortars. The latter mortars continue to expand and three notable expansions are registered between 500 to $600^{\circ} \mathrm{C}, 800$ to $900^{\circ} \mathrm{C}$, and 900 to $1000^{\circ} \mathrm{C}$. The former two phases of expansion are related to the transformation of $\alpha$ to $\beta$-quartz

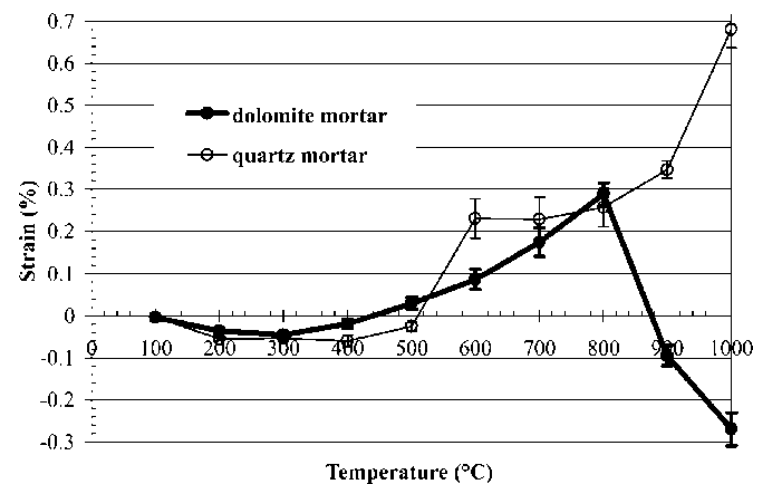

Fig. 4 The linear unrestrained movement of the quartz and dolomite specimens as a function of temperature. The residual deformation is measured after cooling to room temperature.
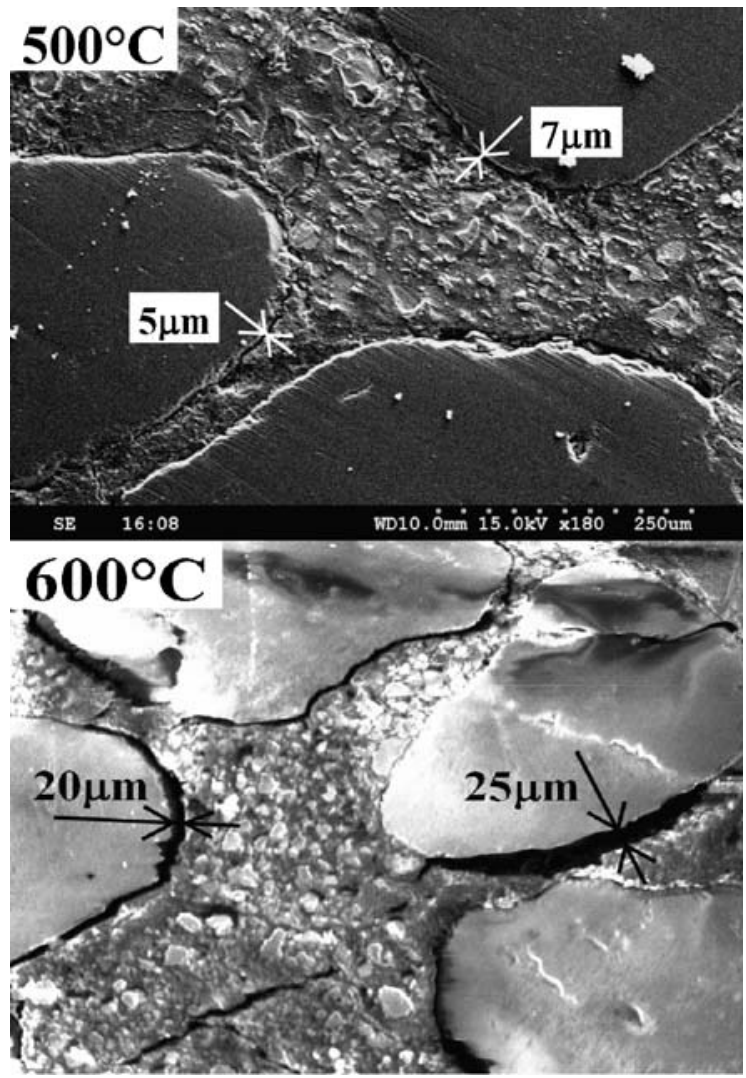

Fig. 5 The interface between the cement paste and quartz aggregate before transformation $\left(500^{\circ} \mathrm{C}\right)$ and after the transformation of $\alpha$ to the $\beta$-quartz polymorph $\left(600^{\circ} \mathrm{C}\right)$.

and $\beta$-quartz to $\beta$-tridymite, respectively. As a result, the absolute linear expansion at 600 and $900^{\circ} \mathrm{C}$ is 0.23 and $0.35 \%$, respectively. The reason for the last expansion from 900 to $1000^{\circ} \mathrm{C}$ needs further investigation. At $1000^{\circ} \mathrm{C}$, the total measured expansion of the quartz specimens is about $0.68 \%$.

By contrast, the dolomite mortar expands exponentially from 300 to about $800^{\circ} \mathrm{C}$ and the corresponding linear strain varies from -0.045 to $+0.29 \%$. The expansion ends at about $800^{\circ} \mathrm{C}$ and is opposed by a rapid contraction at an average rate of about $0.0028 \% /{ }^{\circ} \mathrm{C}$ due to the mass loss. Thus, the net linear unrestrained movement at $1000^{\circ} \mathrm{C}$ is about $0.27 \%$.

As recalled, $\alpha$-quartz is transformed to the $\beta$-quartz polymorph at $573^{\circ} \mathrm{C}$. Figure 5 is a SEM micrograph of flat polished surfaces showing the cracking pattern found in the quartz mortar before and after $\left(600^{\circ} \mathrm{C}\right)$ this transformation. The upper micrograph shows the cracking pattern at $500^{\circ} \mathrm{C}$. The cracking pattern is composed of about $7 \mu \mathrm{m}$ wide cracks that are formed along 
the interfacial transition zone between the aggregate and matrix and other narrower cracks in the matrix. After the conversion, the lower micrograph shows that the width of the cracks increases especially along the quartz boundaries where the cracks' width is as high as $25 \mu \mathrm{m}$.

\subsubsection{Mechanical properties and cracking}

The compressive strengths of the dolomite and quartz specimens after 14 days of ordinary curing are $81 \mathrm{MPa}$ and $60 \mathrm{MPa}$, respectively. Upon heating, the strength of both mortars increases up to about $300^{\circ} \mathrm{C}$ and then decreases. Castillo [29] attributed the strength increase to the stiffening of the cement gel or to the increase of surface forces between the gel particles due to release of adsorbed moisture.

Figure 6 exhibits the variations of the normalized compressive strengths and moduli of elasticity at different temperatures. Three issues deserve further attention. The effect of temperature on the strength of the quartz mortar is by far greater than the corresponding effect on the dolomite mortar. Accordingly, at $300^{\circ} \mathrm{C}$, the relative strength of the quartz mortar is $180 \%$, whereas that of the dolomite mortar is only $118 \%$. Second, above $300^{\circ} \mathrm{C}$, the strength of the quartz mortar decreases faster than the corresponding strength of dolomite. Thirdly, the change in the moduli of elasticity does not follow, at least not linearly, the change in compressive strength. One explanation might be that the modulus of elasticity is greatly affected by the presence of cracks; thereby, the increase of the moduli up to $300^{\circ} \mathrm{C}$ is less distinct than the increase of the compressive strengths.

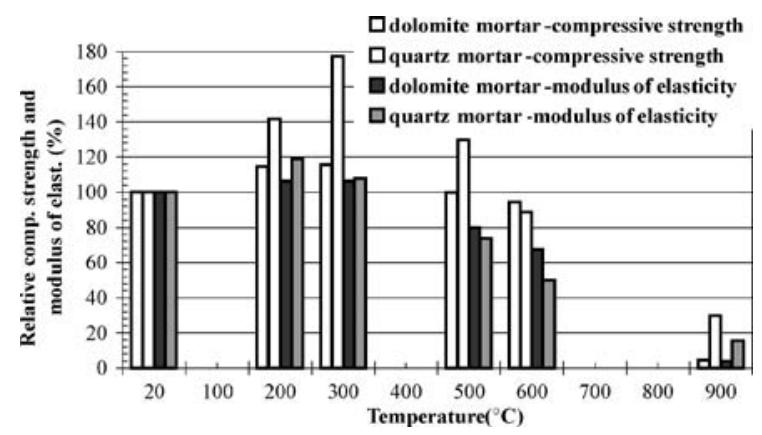

Fig. 6 Relative compressive strengths and moduli of elasticity of dolomite and quartz mortars as a function of temperature.
At $900^{\circ} \mathrm{C}$, both mortars have almost lost all their mechanical properties. The greater decrease registered with the dolomite mortar is attributed to the complete dissociation of the dolomite and the severe mass loss that is associated with this process. Consequently, the compressive strength of the dolomite mortar at $900^{\circ} \mathrm{C}$ is only $3.9 \mathrm{MPa}$, whereas that of the quartz mortar 17.9 MPa.

Both mortars develop mosaic cracking patterns that are presented in Fig. 7. It is evident that at $500^{\circ} \mathrm{C}$ the cracking pattern of the quartz mortar is more distinct and has a closer-spacing and uniform distribution than the companion dolomite mortar. The uniform mosaic network might be attributed to the spherical and nearly monosize grains of quartz sand used in this study. At $600^{\circ} \mathrm{C}$, the cracking pattern of the quartz mortar intensifies, so does the crack width, while the cracking pattern of the dolomite mortar remains about the same.

As can be predicted from the rapid degradation of the mechanical properties, the crack width is markedly increased at higher temperatures. At $800^{\circ} \mathrm{C}$, the crack width of the quartz mortars is increased over than twofold and further increases with the rising temperature. Thus, at $1000^{\circ} \mathrm{C}$ the cracks width approaches about $60 \mu \mathrm{m}$.

The cracking pattern of the dolomite at $800^{\circ} \mathrm{C}$ is about the same as that of the quartz at $600^{\circ} \mathrm{C}$, but at higher temperatures it intensifies due to the dissociation of the dolomite and the subsequent mass loss. Therefore, at $1000^{\circ} \mathrm{C}$, the cracking pattern of the two series is about the same.

\subsection{Effects of addition of polypropylene fibers}

PP fibers were introduced at a constant dosage of $2 \mathrm{~kg} / \mathrm{m}^{3}$. At such low dosages the fibers have little or no effect on the mechanical properties, rather at ordinary temperature, fibers at this dosage are added to control the plastic shrinkage. As noted previously, the role of fiber addition at high heating rates lies in elimination of potential spalling. The following aims at making connection between the transport properties and spalling.

\subsubsection{Effects of fiber addition on physical properties}

The effects of PP fibers on the transport properties were investigated by conducting permeability measurements on specimens cured at room temperature and specimens 
Fig. 7 Optical microscope images of the mosaic cracking patterns that were formed in the dolomite (D) and quartz (Q) mortars at various temperatures.

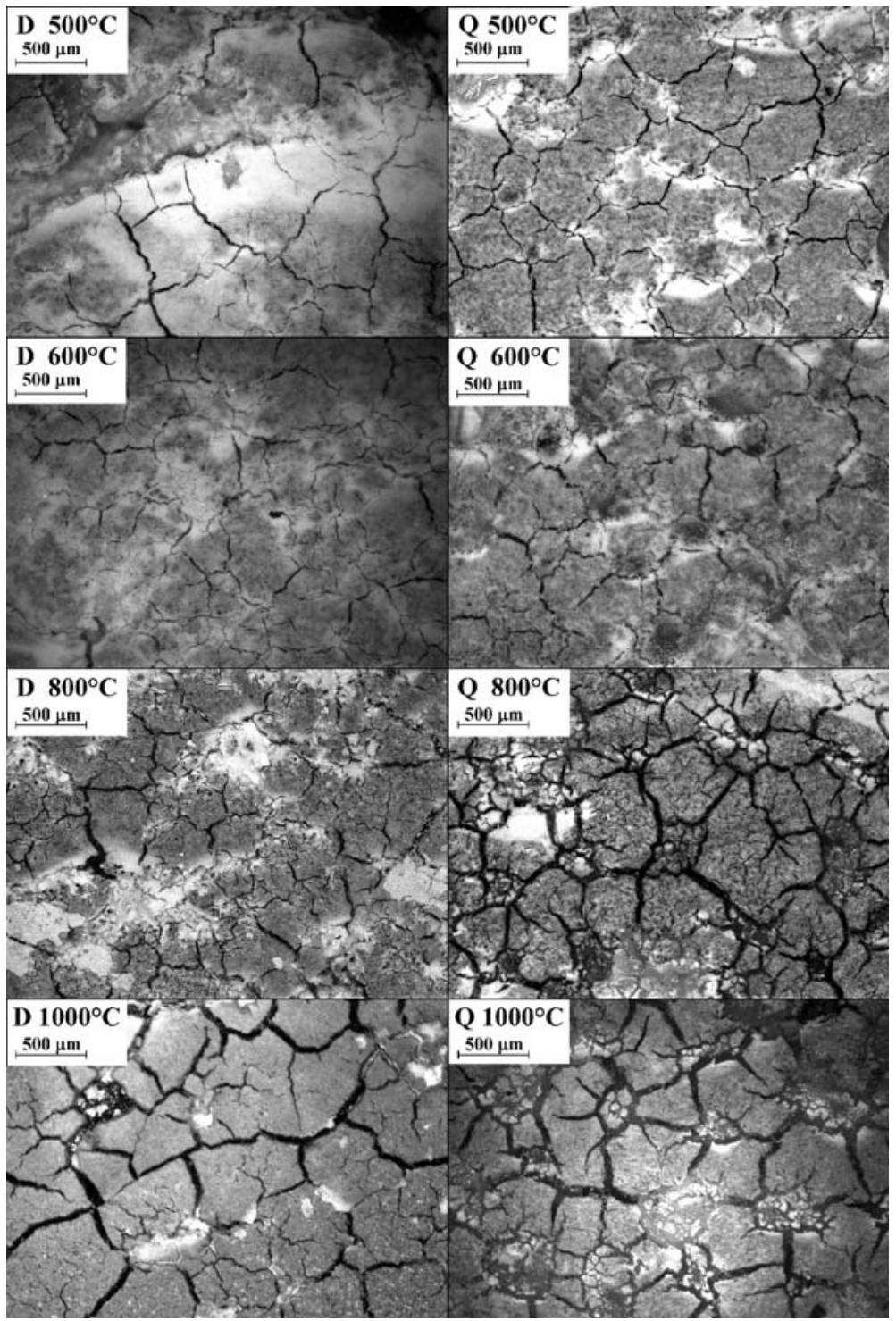

subjected to relatively low temperatures of 100 and $200^{\circ} \mathrm{C}$.

The results of the water permeability test are plotted in Fig. 8 along with the ranges of the experimental errors. In view of the experimental errors, the permeability of the dolomite and the quartz mortars at room temperatures is about the same. However, it is clear that both heating and fiber addition increase the permeability. Up to $100^{\circ} \mathrm{C}$, the increase of the permeability is relatively small, but a distinct increase takes place from 100 to $200^{\circ} \mathrm{C}$, and this increase is further augmented in the presence of fibers. For example, at $200^{\circ} \mathrm{C}$, the average permeability of mortars with fibers is about 1.7 times higher than the companion specimens with no fibers.

In order to verify the adverse effects of fibers on the transport properties, additional set of specimens with and without fibers was prepared, cured for 14 days in water, and then transferred to a controlled environmental chamber kept at 50\% RH. The mass loss of the specimens was recorded periodically by weighing the specimens up to 50 days. Figure 9 provides the mass loss results. In an agreement with the permeability data, the type of aggregate has little effect on the mass loss. However, a distinct increase in the mass loss is recorded with fibers and the mass loss at 48 hours of the 


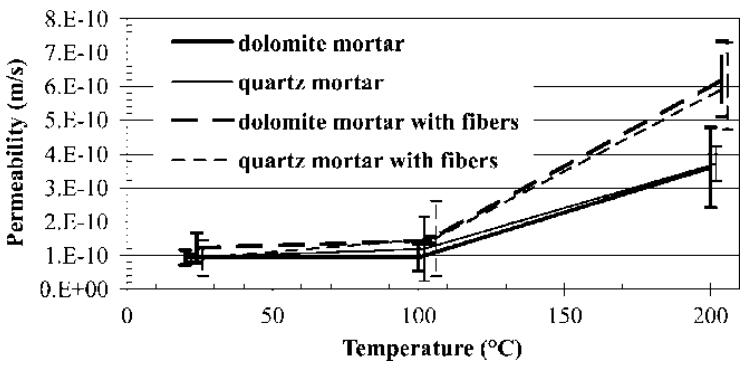

Fig. 8 Water permeability of the mortars with and without PP fibers as a function of temperature.

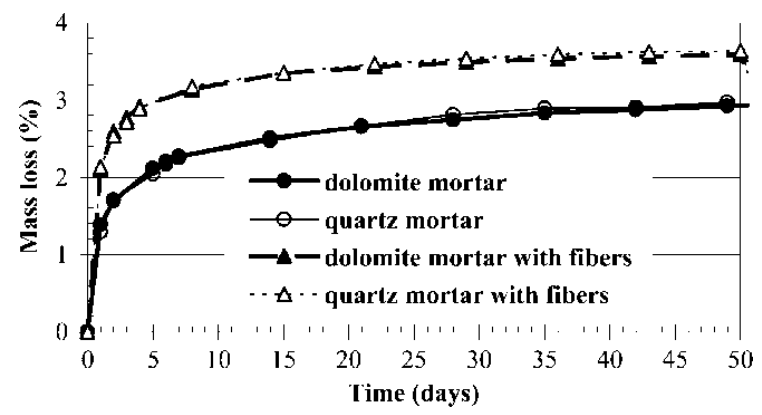

Fig. 9 Mass loss of the mortars with and without fibers at room temperature and $50 \% \mathrm{RH}$.

specimens with fibers is over than 1.5 times than the mass loss of the specimens without fibers.

A further linkage between the transport properties, fibers, and microstructure is provided in Fig. 10. The SEM micrographs show the interfaces between the matrix and the fibers of the unheated specimens (upper), and specimens heated to $200^{\circ} \mathrm{C}$ (lower). The images show that at a room temperature the interface with the fibers is porous and semi-continuous narrow cracks accompany the fiber surfaces. Admittedly, some of this microcraks might be associated with specimen preparation and shrinkage of the specimens in the SEM chamber. Nonetheless, this parting is narrow. By contrast, after heating, this parting is widened and becomes continuous. This observation supports the previous results and explains why the permeability and mass loss at $200^{\circ} \mathrm{C}$ are markedly higher than the corresponding values at room temperature.

Of interest, despite the greater humidity loss of the specimens with fibers, the shrinkage of the former is smaller than that of the specimens with no fibers. Plots of the unrestrained linear movement of the unheated specimens with and without fibers are given in Fig. 11. The specimens underwent a normal curing under water for 14 days and than were placed in a controlled

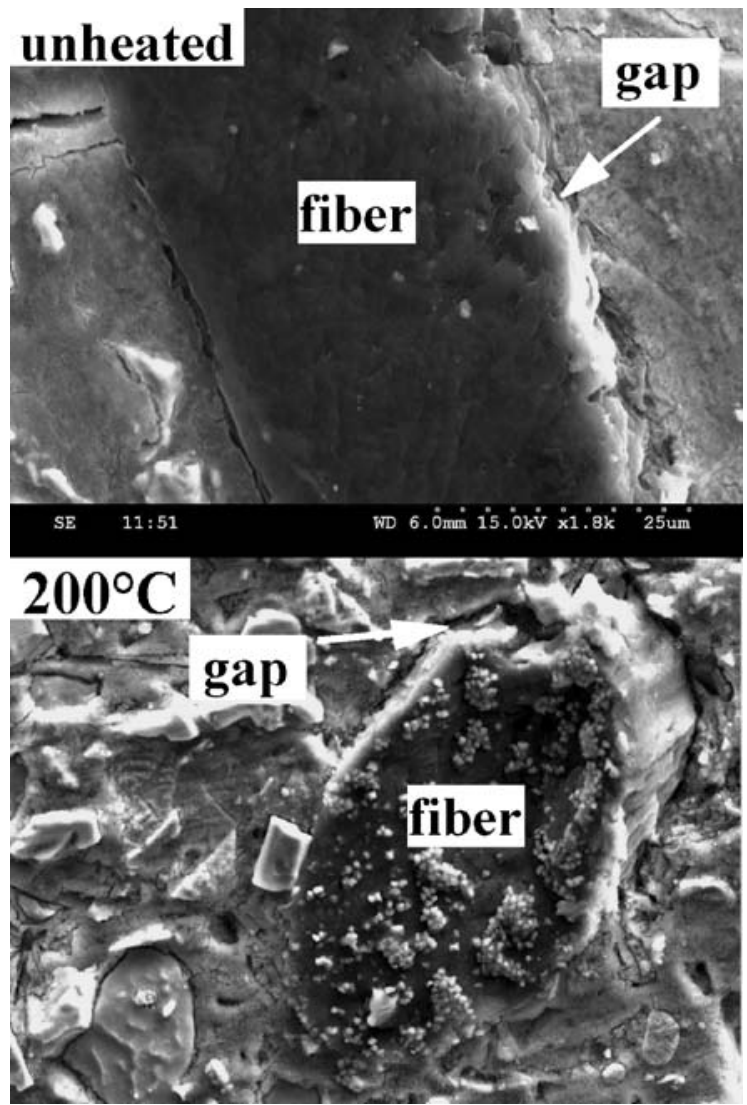

Fig. 10 SEM micrograph showing the porous interface form between PP fiber and the matrix in unheated specimen and the gap formed between the fiber and matrix in a specimen subjected to $200^{\circ} \mathrm{C}$.

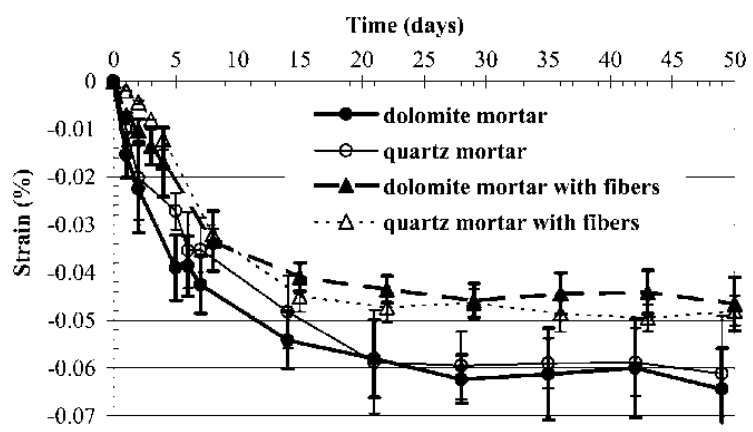

Fig. 11 Shrinkage of mortars with and without fibers at room temperature and $50 \% \mathrm{RH}$.

environmental chamber at $50 \% \mathrm{RH}$ up to 50 days. Similar to the permeability and mass loss results, the type of aggregate has little effect on the shrinkage, but addition of fibers reduces the unrestrained strain from over than -0.0006 to less than -0.0005 . 


\subsubsection{Effect of fibers on spalling}

Cementitious materials may undergo explosive spalling due to pressure build-up of volatiles at temperatures as low as $200^{\circ} \mathrm{C}$. The pressure build-up is related to the strength, composition, and more specifically, to the content of vapors that are formed at a specific temperature on one hand, and the pressure relief due to permeability on the other hand. Consequently, the susceptibility to spalling increases with the increase of the content of water and other volatiles, heating rate, and specimen size, and decreases with the increase of permeability [2]. Therefore, high-strength concrete which is associated with low w:c and permeability, is more susceptible to spalling than ordinary concrete. To this end, it was also suggested that spalling might be related to differential stresses between the aggregate and paste due to differences in thermal expansion [30,31].

Although the spalling temperature is lower than $500^{\circ} \mathrm{C}$, in this study, only specimens heated up to a nominal $500^{\circ} \mathrm{C}$ and higher spalled. Specimens heated to lower temperatures never spalled. This was probably related to the temperature gradients between the oven and the specimens that allowed the oven temperature to be $500^{\circ} \mathrm{C}$, but at the same time, the specimens' temperature was below the "critical" spalling temperatures.

In agreement with others, it was found that spalling is a stochastic process. For example, $18 \%$ of 43 experiments conducted with prisms $25 \times 25 \times 180 \mathrm{~mm}$ in dimensions that were made of plain quartz mortar and heated to $500^{\circ} \mathrm{C}$ or higher underwent explosive spalling, whilst none of the companion dolomite prisms spalled. However, by reducing the surface to volume ratio, all the cylinders with dimensions of $\varnothing 76 \times 25 \mathrm{~mm}$ made of dolomite mortar spalled. Some of the specimens that underwent violent explosive were equipped with a thermocouple, and it was noted that the spalling took place in the temperature range of 230 to $250^{\circ} \mathrm{C}$.

By contrast, none of the mortars made with quartz or dolomite aggregate and contained PP fibers underwent violent explosion.

\section{Discussion}

Fire resistance of a structural element is evaluated by the length of time that the element continues to perform its functions. It implies that the fire resistance is referred to the element rather than the materials comprising the element. Nonetheless, it is imperative that the fire performance of the materials would not compromise the fire resistance of the structural element.

The fire performance needs to be evaluated according to several aspects: the ability to provide a thermal barrier, volume stability, and mechanical properties. Figure 2 indicates that the mortars under consideration provide a good thermal resistance up to about $200^{\circ} \mathrm{C}$. In this range, the rate of heating is gradually increased and the dominant features are the release of evaporable and non-evaporable water from the C-S-H and a notable endothermic peak that is centered at about $110^{\circ} \mathrm{C}$. This peak corresponds to the temperature in which ettringite and monosulfate give off water. It is evident, therefore, that the thermal resistance is increased as the agg:c decreases, w:c increases, and the cement is rich in alumina and sulfate.

Due to the depletion in the content of the nonevaporable water bound in the $\mathrm{C}-\mathrm{S}-\mathrm{H}$, the heating rate increases sharply in the range of 200 to $250^{\circ} \mathrm{C}$. To be noted that the gradual decline of the heating rate from 250 to $1000^{\circ} \mathrm{C}$ is not related to chemical reactions, but rather it is an artifact that is attributed to the failure of the heating elements to provide the nominal heating rate. In that way, this monotonous decline roughly delineates the actual heating rate that the specimens are subjected to and this monotonous decline can be regarded as a baseline.

Above $300^{\circ} \mathrm{C}$, the quartz mortar thermograph differs from the corresponding dolomite in two features: (a) the baseline of the quartz mortar is higher than that of the dolomite, and (b) it has only one endothermic peak from about 480 to $550^{\circ} \mathrm{C}$ that corresponded to the breakdown of portlandite, whilst that of the dolomite has other three conspicuous endothermic peaks that are centered at about 630,750 , and $900^{\circ} \mathrm{C}$. The latter peaks are associated with the dissociation of the dolomite (Fig. 3).

The high baseline of the quartz mortar is attributed to the higher thermal conductivity of quartz.

Because of the above endothermic reactions, the temperature at the center of the dolomite specimens is lower by about $60^{\circ} \mathrm{C}$ at $750^{\circ} \mathrm{C}$ and about $90^{\circ} \mathrm{C}$ at $900^{\circ} \mathrm{C}$ than the corresponding temperatures in the quartz mortars, and these differences may increase as the agg:c increases. Indeed, field experience has shown that concretes made with quartz aggregate or acid rocks in which quartz is a major constituent have poor fire performance [32]. 
The rapid heating rates of the dolomite specimens between the endotherms that peak at about 830 and $930^{\circ} \mathrm{C}$, are probably related to the increase in conductivity due to the dolomite mass loss (Fig. 3).

Several opposing factors affect the volume instability including the shrinkage of the cement paste, normal thermal expansion of the individual constituents, phase transformation of quartz, and dolomite dissociation. Up to $300^{\circ} \mathrm{C}$ (dolomite mortar) or $400^{\circ} \mathrm{C}$ (quartz mortar), the dominant mechanism is shrinkage. However, because of thermal expansion, above $500^{\circ} \mathrm{C}$ all the specimens rapidly expand. The exact temperature in which the transformation from shrinkage to expansion takes place depends therefore on the agg:c. Similarly, the spacing of the network of the mosaic cracking and the crack width depend on the content of quartz and dolomite and perhaps their grain size. Above $800^{\circ} \mathrm{C}$, the actual rate of contraction of mixtures containing dolomite aggregate will be varied according to the agg:c, but will take place at about the same temperature. However, if calcite aggregate are used, the transformation from expansion to contraction will take place at higher temperatures approaching $900^{\circ} \mathrm{C}$.

Interpretation of the data suggests that changes in the mechanical performance take place in three thermal zones; low $\left(<300^{\circ} \mathrm{C}\right)$, intermediate $\left(300-600^{\circ} \mathrm{C}\right)$, and high $\left(>600^{\circ} \mathrm{C}\right)$. It is shown that the compressive strength increases in the low thermal zone, moderately decreases in the intermediate one, and rapidly decreases in the high thermal zone. The same applies to the modulus of elasticity with two reservation; the modulus does not increase as much as the compressive strength in the low thermal zone, but decreases faster than the former in the other two thermal zones. The main factors that affect the mechanical performance are attributed to the following: shrinkage and mass loss of the paste, aggregate expansion, phase transformation of quartz, and dissociation and mass loss of dolomite. In addition, the rapid deterioration of properties at the high thermal zone might also relate to the disintegration of the C-S-H [33].

Since the mechanical performance is strongly related to cracking and since cracking is affected by the agg:c, type of aggregate, heating rate, specimen geometry, etc, the exact temperatures of the above thermal regimes may vary. Nonetheless, similar results are reported in the literature. For example, Handoo et al. [34] placed the beginning of the decline of the compressive strength at $400^{\circ} \mathrm{C}$, whilst Khoury [35] placed it at about $300^{\circ} \mathrm{C}$. It was also noted that the relative deterioration of the modulus exceeds that of the compressive strength [8], probably because the modulus is greatly affected by cracking. In all, it appears that the type of aggregate has a preponderate effect on mechanical performance in the second and third thermal zones.

Several authors related the beneficial effects of addition of PP fibers on spalling to fiber melting or shrinkage $[11,36,37]$. It is shown, however, that incorporation of PP fibers increases the transport properties of the unheated specimens as well as the heated specimens. SEM analyses point to the porous interface that is formed between the fiber and the matrix at room temperature that is widened and transformed into continuous cracks at $200^{\circ} \mathrm{C}$. That explains the rapid increase of the transport properties from room to $100^{\circ} \mathrm{C}$ and 100 to $200^{\circ} \mathrm{C}$. The relieve of pore pressure is attributed therefore to the porous and week interface between the PP fibers and the matrix that readily cracks upon formation of thermal stresses rather than fiber melting.

\section{Conclusions}

The fire performance of the materials studied is related to several factors including thermal conductivity, volume stability, mechanical properties, and elimination of violent explosion. The following highlights the main considerations:

1. The type of aggregate has a preponderate effect on the fire performance as it affects the volume stability, porosity, mass loss, and microstructure. The key parameters of aggregate are related to thermal expansion, conversion of $\alpha$-quartz to $\beta$-quartz at $573^{\circ} \mathrm{C}$, $\beta$-quartz to $\beta$-tridymite at $867^{\circ} \mathrm{C}$, and dissociation of dolomite in the range of 650 to $930^{\circ} \mathrm{C}$.

2. The cement paste is a good thermal barrier up to about $200^{\circ} \mathrm{C}$. Other endothermic reactions that substantially reduce the heating rate are decomposition of $\mathrm{Ca}(\mathrm{OH})_{2}$ at about $500^{\circ} \mathrm{C}$, and especially dissociation of dolomite over $650^{\circ} \mathrm{C}$.

3. The cracking pattern of quartz mortar differs from that of dolomite mortar by a closer spacing and wider cracks.

4. The mechanical properties vary according to three thermal zones: In the low thermal zone, $<300^{\circ} \mathrm{C}$, the mechanical properties increase or are about the same. In the intermediate zone, 300 to about $600^{\circ} \mathrm{C}$, 
the properties moderately decrease, and in the higher zone, $>600^{\circ} \mathrm{C}$ the properties rapidly decrease.

5. Violent explosion of cementitious materials due to pressure buildup of volatiles can take place at temperatures as low as about $200^{\circ} \mathrm{C}$. Addition of PP fibers effectively prevents explosive spalling due to the substantial increase of the transport properties. That prevention of pore pressure buildup is attributed to the formation of weak and porous interface zone between the fibers and matrix that is readily transformed into continuous cracks upon heating.

Acknowledgements The financial support of the first author within the framework of the project 1 K04111 by Ministry of education is gratefully acknowledged.

\section{References}

1. Neville AM (1981) Properties of Concrete. Pitman Publishing, 3rd Ed, London p. 779.

2. Sullivan PJE (2004) A probabilistic method of testing for the assessment of deterioration and explosive spalling of high strength concrete beams in flexure at high temperature. Cem Concr Composites 26:155-162.

3. Khoury GA, Grainger BN, Sullivan PJE (1985) Transient thermal strain of concrete: literature review, conditions within specimen and behavior of individual constituents. Materials and Structures 37(132):131-144.

4. Malhotra HL (1956) The effect of temperature on the compressive strength of concrete. Materials and Structures 8(22):85-94.

5. Phan LT (1996) 'Fire Performance of High-Strength Concrete: A Report of the State-of-the-Art. NISTIR 5934, Building and Fire Research Laboratory, NIST, Gaithersburg, p. 105.

6. Hammer TA (1992) High strength concrete, Phase 3. SP6 Fire resistance-report 6.2, Spalling Reduction through Material Design, SINTEF, STF70 F92156, Trondheim, Norway.

7. Sanjayan S, Stocks J (1993) Spalling of high-strength silica fume concrete in fire. ACI Mat J 90(2):170-174.

8. Phan LT, Lawson JR, Davis FL (2001) Effects of elevated temperature exposure on heating characteristics, spalling and residual properties of high performance concrete. Mat Structures 34:83-91.

9. Bažant ZP, Thonguthai W (1979) Pore pressure in heated concrete walls: theoretical prediction. Materials and Structures 31(107):67-76.

10. Bilodeau A, Kodur VKR, Hoff GC (2004) Optimization of the type and amount of polypropylene fibers for preventing the spalling of lightweight concrete subjected to hydrocarbon fire. Cem Concr Composite 26:163-174.

11. Sullivan and Associates (2001) Deterioration and spalling of high strength concrete under fire. Offshore Technology Report 2001/074.

12. Bostrom L (2003) Self-compacting concrete exposed to fire. In proc. of 3rd International Symposium on Self-Compacting Concrete, Reykjavik, Iceland.
13. Eurocode 2 (1985) Design of concrete structures, Part 1-2: General Rules-Structural fire design.

14. RILEM TC 44-PHT: 'Properties of materials at high temperatures'.

15. RILEM TC 74-THT, Test methods for high temperature properties.

16. RILEM TC 129-MHT, Test methods for mechanical properties of concrete at high temperatures.

17. Dehn F, Konig G (2003) Fire resistance of different fiber reinforced high-performance concretes. In proc. of High Performance Fiber Reinforced Cement Composites, HPFRCC, Ann Arbor, USA.

18. ASTM C (1988) Making and curing concrete test specimens in the laboratory.

19. ASTM C, (1994) Electrical Indication of Concrete's Ability to Resist Chloride Ion Penetration.

20. Sobczyk K, Kirkner DJ (2001) Stochastic modeling of microstructures. Birkhauser, Boston Basel Berlin.

21. Fenner CN (1913) The stability relations of the silica minerals. Amer Jour Sci 4th 36:331.

22. Berry LG, Mason B (1959) Mineralogy Concepts Descriptions Determinations. W.H. Freeman Company, San Francisco, p. 630.

23. Deer WA, Howie RA, Sussman J (1980) An Introduction to the Rock-Forming Minerals. Longman, London, p. 528.

24. Schneider U, Diederichs U (1981) Physical properties of concrete from $20^{\circ} \mathrm{C}$ up to melting. Parts 1 and 2. Betonwerk and Fertigteiltechnik, Heft 3 and 4.

25. Bažant ZP, Kaplan MF (1996) Concrete at high temperatures, Material properties and mathematical models. Longman, England.

26. Janotka I, Nürnbergerová T, NadL L (2000) Behavior of highstrength concrete with dolomitic aggregate at high temperatures. Mag of Concrete Res 52(6):399-406.

27. Engler P, Santana MW, Mittleman ML, Balasz D (1988) Non-isothermal in situ XRD analysis of dolomite decomposition. The Rigaku Journal 5(1):3-8.

28. Samtami M, Skrzypczak-Janktun E, Dollimore D, Alexander K (2001) Thermal analysis of ground dolomite, confirmation of results using an X-ray powder diffraction methodology. Thermochimica Acta 367-368:297309.

29. Castillo C, Durrani AJ (1990) Effect of transient high temperature on High-Strength Concrete. ACI Material Journal 87(1):47-53.

30. Yu-fang FU (2003) Thermal stresses and associated damage in concrete at elevated temperatures. A thesis for the Degree of Doctor of Philosophy, The Hong Kong Polytechnic University.

31. Phan LT, Lawson JR, Davis FL (2001) Effects of elevated temperature exposure on heating characteristics, spalling, and residual properties of high performance concrete. Materials and Structures 34:83-91.

32. Lea FM (1971) The Chemistry of Cement and Concrete. 3rd ed. Chemical Publishing Company, New York, p. 727.

33. Peng GF, Chan SYN, Anson M (2001) Chemical kinetics of C-S-H decomposition in hardened cement paste subjected to elevated temperatures up to $800^{\circ} \mathrm{C}$. Adv. Cem. Res. 13(2):47-52. 
34. Handoo SK, Agarwal S, Agarwal SK (2002) Physicochemical, mineralogical, and morphological characteristics of concrete exposed to elevated temperatures. Cem. Concr. Res. 32(7):1009-1018.

35. Khoury GA (1992) Compressive strength of concrete at high temperatures: A reassessment. Mag. Concr. Res. 44(161):291-309.
36. Kalifa P, Chene G, Galle Ch, (2001) High-temperature behavior of HPC with polypropylene fibers: From spalling to microstructure. Cement and Concrete Research 31:14871499.

37. Hertz KD (2003) Limits of spalling of fireexposed concrete. Fire Safety Journal 38:103116. 